Claremont Colleges

Scholarship@ Claremont

All HMC Faculty Publications and Research

HMC Faculty Scholarship

1-1-1999

\title{
A Theoretical Study of the Electronic Coupling Element for Electron Transfer in Water
}

Newt E. Miller'99

Harvey Mudd College

Matthew C. Wander'97

Harvey Mudd College

Robert J. Cave

Harvey Mudd College

\section{Recommended Citation}

Miller, N.E.; Wander, M.C.; Cave, R.J. “A Theoretical Study of the Electronic Coupling Element for Electron Transfer in Water," J. Phys. Chem. A. 1999, 103, 1084. DOI: 10.1021/jp983171n

This Article is brought to you for free and open access by the HMC Faculty Scholarship at Scholarship @ Claremont. It has been accepted for inclusion in All HMC Faculty Publications and Research by an authorized administrator of Scholarship @ Claremont. For more information, please contact scholarship@cuc.claremont.edu. 


\title{
A Theoretical Study of the Electronic Coupling Element for Electron Transfer in Water
}

\author{
Newt E. Miller, Matthew C. Wander, and Robert J. Cave* \\ Department of Chemistry, Harvey Mudd College, Claremont, California 91711
}

Received: July 27, 1998; In Final Form: December 18, 1998

\begin{abstract}
The electronic coupling element for electron transfer between a donor and acceptor in water is examined using simulations combining molecular dynamics and semiempirical quantum mechanics. In the first phase of the simulations a model donor and acceptor are solvated in water, using realistic potentials. Following equilibration, molecular dynamics simulations are performed with the donor, acceptor, and water at approximately $300 \mathrm{~K}$, under periodic boundary conditions. In the second phase of the simulation, the electronic coupling element between the donor and acceptor is calculated for a number of time slices, in the presence of the intervening water molecules (those having a nonnegligible effect on the coupling element at the given distance). Finally, a subset of these configurations is used to investigate the donor-acceptor energy dependence of the coupling by varying the model donor and acceptor. It is found, contrary to a number of previous theoretical results, that water significantly increases the electronic coupling element at a given donor-acceptor separation. The value for $\beta$ using INDO wave functions is estimated to be $2.0 \AA^{-1}$ and is found to depend weakly on the identity of the donor and acceptor. Comparison with ab initio results for a subset of the configurations or using idealized solvent geometries suggests that the ab initio $\beta$ value would be in the range of $1.5-1.8 \AA^{-1}$.
\end{abstract}

\section{Introduction}

From the work of Marcus, ${ }^{1}$ Hush, ${ }^{2}$, Levich and Dogonadze, ${ }^{3}$ and others, ${ }^{4,5}$ solvent is known to play an important role in controlling the rate of electron transfer (et) in solution. The wellknown Marcus-Hush outer sphere "reorganization energy" arises from dielectric polarization effects in response to the transferring electron, and can lead to decreases in the rate of et in highly polar solvents. In addition, solvent dynamics can also play a significant role in determining the rate of et, particularly for fast electron transfer, and a number of theoretical studies have examined the effects of slow solvent relaxation when et is fast. ${ }^{6,7}$ Finally, the possibility exists that solvent can affect the rate of nonadiabatic et via a superexchange mechanism. In this case, the solvent potentially alters the electronic coupling element $\left(H_{\mathrm{ab}}\right)$, found in the expression for the rate constant in quantum-mechanical ${ }^{3,4}$ and semiclassical ${ }^{5}$ expressions for the rate of electron transfer at a given distance $\left(k_{\mathrm{et}} \propto\left|H_{\mathrm{ab}}\right|^{2}\right) .{ }^{8,9}$

The types of reactions in which such solvent-mediated coupling might be important, while not ubiquitous, have nevertheless been discussed in the literature. The experiments of Miller and co-workers ${ }^{10-12}$ involving et in glasses indicate a much slower decay of rate with distance than one would expect were vacuum separating the donor and acceptor. In comparison with model compounds containing rigidly linked donors and acceptors with saturated bridges, ${ }^{13-15}$ the decay with distance in the glasses is slow enough to suggest that solvent, though more weakly interacting, nevertheless significantly increases $H_{\mathrm{ab}}$ at a given donor-acceptor distance, and also significantly decreases its decay with distance. Solvent has also been implicated in controlling the electronic coupling in systems containing solvent-separated ion pairs. ${ }^{16}$ In addition, a number of rigidly linked donor-acceptor pairs, in particularly favorable

* To whom correspondence should be addressed. geometries, have also shown evidence of solvent-enhanced electronic coupling. ${ }^{13,17,18}$

A number of theoretical studies have also examined the effects of solvent on the electronic coupling. The work of Newton and co-workers on the $\mathrm{Fe}\left(\mathrm{H}_{2} \mathrm{O}\right)_{6}{ }^{+3 /+2}$ self-exchange reaction ${ }^{19-21}$ (and other similar self-exchange systems) provided convincing evidence that specific interactions between donor(D)/acceptor(A) and bound solvent (or ligand) could dramatically alter the electronic coupling at a given $\mathrm{D}-\mathrm{A}$ separation. Larsson has shown that water can contribute to an increase in the electronic coupling between a donor and acceptor via a superexchange mechanism. ${ }^{22}$ Two recent studies have also examined the effects of multiple waters on the decay of $H_{\mathrm{ab}}$ with distance, using idealized geometries for sequential addition of waters. ${ }^{15,23}$ In these two studies it was found that water reduced the rate of decay of $H_{\mathrm{ab}}$ with distance and that neither the size nor the decay of $H_{\mathrm{ab}}$ with distance were significantly affected by the water orientation between the donor and acceptor. Theoretical studies of solvent effects on $H_{\mathrm{ab}}$ for the C-clamp compounds of Zimmt and co-workers ${ }^{17}$ have also been performed. ${ }^{24,25}$ In studies that focused on individual solvent molecules, ${ }^{24 a, 25}$ it was shown that solvent molecules can dramatically alter the D-A coupling, via symmetry-breaking and superexchange mechanisms, the latter being by far the larger contributor when solvent is located between $\mathrm{D}$ and $\mathrm{A}$. In molecular dynamics/quantum mechanical studies $^{24 \mathrm{~b}}$ using acetonitrile as solvent, it was found that thermal averaging did not diminish the importance of the bridging acetonitrile, but that solvent external to the region between the donor and acceptor (with up to eight acetonitriles present) had little effect on the coupling.

A number of theoretical studies have attempted to consider the effects of water in nonidealized geometries on $H_{\mathrm{ab}}$. The early study by Larsson ${ }^{22}$ considered a simple superexchange model for the $\mathrm{Fe}\left(\mathrm{H}_{2} \mathrm{O}\right)_{6}{ }^{+3 /+2}$ self-exchange reaction, using averaged water-water interactions and extended Hückel wave functions, 
and suggested the $\beta$ in water was approximately $2.4 \AA^{-1}$. (The quantity $\beta$ is used to characterize the distance dependence of $H_{\mathrm{ab}}$ and is obtained by fits of the functional form $\mathrm{e}^{-\beta R}$ to $\left|H_{\mathrm{ab}}\right|^{2}$ vs distance). Larsson concluded that this value was too large for water to function as an effective superexchange medium for et. Marchi and Chandler ${ }^{26}$ also considered the $\mathrm{Fe}\left(\mathrm{H}_{2} \mathrm{O}\right)_{6}+3 /+2$ self-exchange reaction, using molecular dynamics/quantum Monte Carlo simulations to examine the electronic coupling element in the presence of solvent. They used a one-electron model (explicitly considering only the transferring electron) with pseudopotentials for the donor, acceptor, and waters. They calculated the electronic coupling element for three solvent configurations and concluded that, within their model, water had little effect on the electronic coupling, relative to the value at the given $\mathrm{D}-\mathrm{A}$ distance with no solvent present. More recently, Nitzan and co-workers ${ }^{27-29}$ have examined electron tunneling between parallel plate electrodes with intervening water layers. Using a one-electron model and ignoring water polarizability, ${ }^{27}$ their results indicated that water had, at best, a modest effect on the electronic coupling between the plates. More recent results with polarizable waters (but still within a one-electron framework) suggest water significantly increases the electronic coupling relative to vacuum tunneling. ${ }^{28,29}$

None of the coupled molecular dynamics/quantum mechanical studies discussed above considers all-electron models for the solvent. Our previous ab initio results ${ }^{23}$ suggest that this may be a significant omission. Although the geometries examined in our studies were idealized, we found little orientation dependence for the superexchange effects induced by water, and we obtained evidence to suggest that water's effects were due largely to hole-type superexchange (i.e., the electronic coupling was propagated to a large degree through the occupied orbitals of water). To the extent this is true, pseudopotential models will not be able to describe water as a superexchange medium. However, it is also possible that the enhancement of $H_{\mathrm{ab}}$ obtained in our ab initio work was artificially large due to (a) neglect of more distant solvent (e.g., destructive interference effects), or (b) consideration of only a few of the possible solvent geometries accessible at room temperature. In the present study we seek to address these two questions, using molecular dynamics (MD) to generate donor-solvent-acceptor configurations, and semiempirical quantum mechanics to calculate the electronic coupling element. In the MD simulations we use several short-time simulations to examine a variety of donoracceptor distances and water configurations. In the quantum mechanical calculations we performed systematic studies to determine which solvent molecules have a significant effect on $H_{\mathrm{ab}}$, and perform most of the calculations of $H_{\mathrm{ab}}$ explicitly treating only these waters. We also compare our semiempirical methods to ab initio results on the same systems in a number of cases, and find reasonable agreement, not only for $\beta$ but for the value of $H_{\mathrm{ab}}$ itself. The results also show, in agreement with our previous $a b$ initio results, that intervening water between a donor and acceptor can produce a dramatic increase in $H_{\mathrm{ab}}$ at a given distance.

The majority of the calculations presented below consider $\mathrm{Zn}+\mathrm{Zn}^{+}$as the electron donor and acceptor, since this system has been treated previously at the ab initio level. ${ }^{23,30}$ Following discussion of the solvated $\mathrm{Zn}_{2}{ }^{+}$results several other donoracceptor pairs $\left(\mathrm{Li}_{2}{ }^{+}, \mathrm{Be}_{2}{ }^{+}, \mathrm{Na}_{2}{ }^{+}, \mathrm{Mg}_{2}{ }^{+}, \mathrm{Cu}_{2}{ }^{+}\right)$are examined at the semiempirical and/or ab initio level in order to assess the donor-acceptor energy-dependence of the conclusions drawn from the $\mathrm{Zn}$ data.

In the following section we outline the theoretical methods employed for both the Molecular Dynamics simulations and the quantum mechanical calculation of $H_{\mathrm{ab}}$. In section 3 we present our results and discuss the results in section 4. Concluding remarks are presented in section 5 .

\section{Computational Methods}

2.1. Molecular Mechanics. We used a flexible water model, defined by the TIP3P charges, equilibrium bond lengths and angles, and van der Waals constants, ${ }^{31}$ with internal force constants taken from the study of Dang and Pettitt ${ }^{32}$ (OH stretch, $\mathrm{HOH}$ bend, and HH Urey-Bradley term from their flexible TIP model). While intramolecular motion does not appear to have a significant effect on the electronic coupling (see below), a model of this type allows for its examination, and may also lead to somewhat better water structure than a rigid model. ${ }^{33}$ This water model yields a radial distribution function for water $\left(\sim 300 \mathrm{~K}, 1 \mathrm{~g} / \mathrm{cm}^{3}\right)$ from NVE dynamics of similar quality to a variety of other water potentials. ${ }^{34}$ In particular, it reproduces the positions of the second and third peaks in goo better than the rigid TIP3P model. Thus, we expect our distance dependence to be fairly representative of that which would be observed in water.

In the MD simulations the donor and acceptor were modeled as neutral $\mathrm{Zn}$ atoms with van der Waals radii and energies of $2.0 \AA$ and $0.15 \mathrm{kcal} / \mathrm{mol}$. This is an artificially large radius compared to $\mathrm{Zn}$ ions in solution, but by this choice we ensure that the $\mathrm{Zn}$ are weakly perturbed by the waters, and we can thus ascribe the solvent effects on the coupling largely to superexchange rather than to energetic or non-Condon effects (see below). In addition, the $\mathrm{Zn}$ were left uncharged in the MD simulations to avoid polarization of the water structure in the simulations. In making this approximation we thus neglect effects on the coupling element that might arise from the ordering of water near a charged D or A. The results presented below which compare $\beta$ in idealized (ordered) and nonidealized geometries indicate that differences can arise in the two cases where ordering persists over a large distance. However, we are mainly interested in attempting to model the large distance decay of $H_{\mathrm{ab}}$, where one expects the $\mathrm{D}$ or A charge to be screened to a large extent, and the water geometries beyond the screening lengths to be similar to those of pure water. One can thus take our atomic D or $\mathrm{A}$ as a model for solvated/screened ions in solution, and relevant for modeling the long-range decay of $H_{\mathrm{ab}}$ beyond the locally polarized environment. Since we are primarily interested in the long-range decay of $H_{\mathrm{ab}}$, any local polarization actually present in solution should only modify the size of $H_{\mathrm{ab}}$, not its variation with increasing number of intevening waters.

Molecular Dynamics trajectories were generated for the two $\mathrm{Zn}$ in a box of 598 waters, with periodic boundary conditions and an overall density of $1.009 \mathrm{~g} / \mathrm{cm}^{3}$ (two waters in a sample originally having density of $1 \mathrm{~g} / \mathrm{cm}^{3}$ were replaced by $\mathrm{Zn}$ atoms, the new structure was minimized, and then dynamics runs were initiated). Ewald sums were used for van der Waals and Coulomb terms and our integration time step was 0.0005 ps (Verlet leapfrog algorithm). All MD simulations were performed using Cerius ${ }^{2} .{ }^{34}$

The time slices for the calculation of $H_{\mathrm{ab}}$ were taken from three trajectories of lengths from 5-25 ps (average temperatures from 280 to $298 \mathrm{~K}, \pm 7 \mathrm{~K}$ for each trajectory), and the data for Figure 1 accumulated from the union of the sets of slices. Since the $\mathrm{Zn}$ have a tendency to drift from the center of the box with time, and because we wanted to ensure that no edge effects arose when specific waters were selected in the calculations of 


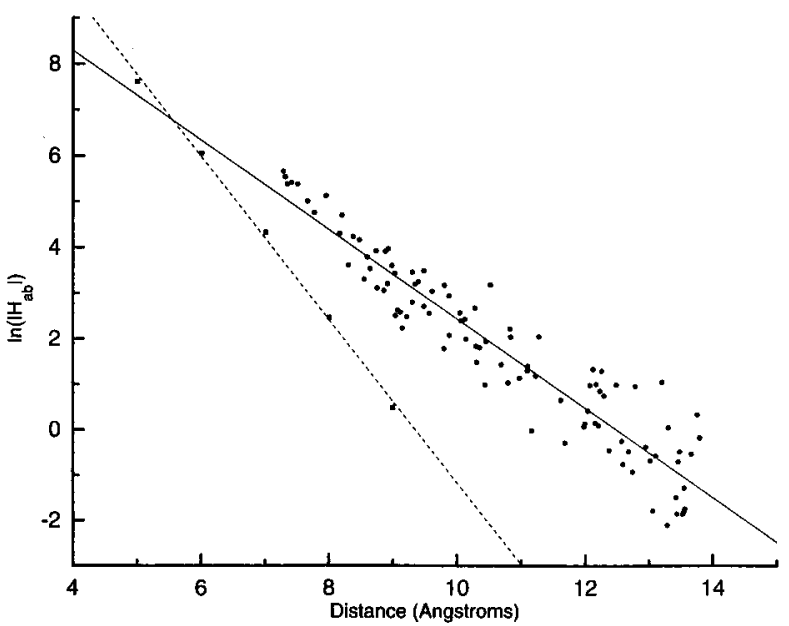

Figure 1. Plot of $\ln \left|H_{\mathrm{ab}}\right|$ vs $R_{\mathrm{ZnZn}}\left(H_{\mathrm{ab}}\right.$ in $\left.\mathrm{cm}^{-1}\right)$ for $\mathrm{Zn}_{2}{ }^{+}$with (solid line, circles) and without (dashed line, squares), water present. The data are based on INDO wave functions and the GMH analysis, as described in sections 2 and 3 . The value of $\beta$ with water present is $1.96 \AA^{-1}$ and that without water present is $3.57 \AA^{-1}$.

$H_{\mathrm{ab}}$, we chose to gather data from several short time runs rather than one or two longer trajectories. Each new trajectory was initiated by replacing two water molecules from an equilibrated box of waters with $\mathrm{Zn}$ atoms, followed by reequilibration, and dynamics. These time slices, containing approximately 1800 atoms, were still too large for us to perform $H_{\mathrm{ab}}$ calculations with the entire set of waters present (our version of ZINDO has a 500 atom limit); thus we explored ways to reduce the number of waters explicitly considered in the electronic structure theory calculations. On the basis of a series of test calculations, and previous results, ${ }^{23,30,36}$ it is expected that only waters between the two $\mathrm{Zn}$ atoms will have a significant effect on the coupling. Our truncation scheme focuses on these intervening waters, which comprise all waters falling within a sphere of radius $\mathrm{R}_{\mathrm{ZnZn}} / 2+1 \mathrm{D}$, the center of which is located at the midpoint of the $\mathrm{Zn}-\mathrm{Zn}$ line of centers. If any atom of a water falls within this sphere the water is included in the electronic structure theory calculations. With this procedure the approximate number of waters treated for $R_{\mathrm{ZnZn}}=7 \AA$ is 15 , while at $R_{\mathrm{ZnZn}}=12 \AA$ the number of waters included is about 50 . To examine whether the $H_{\mathrm{ab}}$ values obtained from these truncated sets were converged, we chose several time slices and selected successively larger radius spheres for water inclusion $\left(R_{\mathrm{ZnZn}} / 2+2, R_{\mathrm{ZnZn}} / 2\right.$ $+3)$. We found that the $H_{\mathrm{ab}}$ values changed by no more than $11 \%$ with these larger radii, even though the number of waters included doubled or tripled, indicating that our standard radius represents a sufficiently converged set of waters for our purposes. These spheres with larger radii also include more waters outside the $\mathrm{Zn}-\mathrm{Zn}$ line of centers, and thus indicate that nonintervening waters have a modest effect on the electronic coupling.

To examine the sensitivity of $H_{\mathrm{ab}}$ and $\beta$ to donor-acceptor orbital energies for nonidealized water geometries we selected a subset of the above time slices and substituted other atomic species $(\mathrm{Cu}, \mathrm{Be}, \mathrm{Mg})$ for the $\mathrm{Zn}$ atoms. Thus, while no new MD simulations were performed for these donor-acceptor pairs, one can nevertheless assess how a given set of water configurations would alter $H_{\mathrm{ab}}$ and $\beta$ for these D-A pairs.

2.2. INDO/GMH Calculations. In the majority of our calculations of $H_{\mathrm{ab}}$ the donor and acceptor were taken to be $\mathrm{Zn}$ and $\mathrm{Zn}^{+}$, respectively. This model system represents an idealization, but considerable data has been obtained at the ab initio level on et involving $\mathrm{Zn}_{2}{ }^{+}$with and without solvent present. Thus, the present results can be compared with them for calibration purposes. Other donor-acceptor pairs used in the INDO calculations were $\mathrm{Cu}_{2}{ }^{+}, \mathrm{Mg}_{2}{ }^{+}$, and $\mathrm{Be}_{2}{ }^{+}$. The wave functions used to evaluate $H_{\mathrm{ab}}$ are from INDO/S CI calculations, using the Zerner group parametrization of INDO. ${ }^{37}$ Two adiabatic CI states are required in order to perform the GMH analysis. The results were relatively insensitive to the choice of occupied orbitals on which to base the CI, but in order to yield a more balanced treatment of the donor and acceptor we chose the RHF orbitals of the neutral $\mathrm{M}_{2}$ and water system for $\mathrm{Zn}, \mathrm{Mg}$, or Be (RHF orbitals for $\mathrm{Cu}_{2}^{+2}+$ water for the $\mathrm{Cu}_{2}{ }^{+}$ $\mathrm{D}-\mathrm{A}$ pair), and then in the CI portion of the calculation we removed or added an electron to explicitly treat $\left(\mathrm{M}_{2}-\text { water }\right)^{+}$. In all cases the HOMO and HOMO-1 were localized on the two $M$, and were composed primarily of the $M$ valence $s$ orbitals. The CI calculation was based on single excitations from two configurations ((HOMO-1 $)^{2}(\mathrm{HOMO})^{1}$ and $(\mathrm{HOMO}-1)^{1}$ $\left.(\mathrm{HOMO})^{2}\right)$. For each configuration, excitations were allowed from the HOMO-1 and HOMO, into the lowest eight virtual orbitals. Test calculations indicate that the results for $H_{\mathrm{ab}}$ are relatively insensitive to expansion of the occupied or virtual space.

Much as one must make choices of basis sets in an ab initio calculations, choices of parameters are made (often implicitly) in the use of semiempirical method. We have used the spectroscopic parameters in $\mathrm{ZINDO}^{37}$ and chose the $\mathrm{O}$ resonance integral parameter (denoted $\beta$ as well, not to be confused with the $\beta$ value used to characterize the decay of $\left|H_{\mathrm{ab}}\right|^{2}$ with distance) to be that suggested for solution calculations $(-34.0)$ rather than the gas-phase value $(-54.0)$. Each yielded similar decay behavior for $H_{\mathrm{ab}}$, but the former yielded somewhat larger values of $H_{\mathrm{ab}}$ in the solvated systems, in better agreement with ab initio results.

The calculation of $H_{\mathrm{ab}}$ is performed using the Generalized Mulliken-Hush ${ }^{30,36}$ (GMH) approach. The GMH method is based on the Mulliken-Hush ${ }^{38,39}$ treatment of charge-transfer transitions, but is nonperturbative and requires no a priori estimation of the charge-transfer distance. In fact, it provides an independent estimate of this quantity along with $H_{\mathrm{ab}}$. Finally, it can be used for any number of states and can be applied at any geometry, not merely that of the crossing point between donor and acceptor diabatic states. We use a two-state model in the present article, and the quoted $H_{\mathrm{ab}}$ values are those for the geometry for the given time slice. Standard semiclassical ${ }^{5}$ and quantum theories ${ }^{3,4}$ generally require the value of $H_{\mathrm{ab}}$ at the lowest energy point along the crossing seam for the relevant diabatic surfaces, but given the number of coordinates and weak interactions in our systems, the search for this geometry at each time slice would not be feasible computationally. In the cases we examine here the donor and acceptor diabatic states are generally not degenerate (differing by from 100 to $6000 \mathrm{~cm}^{-1}$, with some differences as large as $15000 \mathrm{~cm}^{-1}$ ), but the Condon approximation suggests that the coupling at the transition state geometry should be similar to what one obtains at these geometries. In fact, using model calculations we show below that for energy differences below about $6000 \mathrm{~cm}^{-1}, H_{\mathrm{ab}}$ should vary no more than $10 \%$, and variations of this order will have no effect on our conclusions.

2.3. Ab Initio Calculations. To calibrate the INDO-based $H_{\mathrm{ab}}$ results, we also present data obtained for $\mathrm{M}_{2}\left(\mathrm{H}_{2} \mathrm{O}\right)_{n}{ }^{+}(\mathrm{M}=$ $\mathrm{Zn}, \mathrm{Be}, \mathrm{Mg}, \mathrm{Li}, \mathrm{Na}$ ) in several geometries using ab initio methods similar to those applied in a previous study. ${ }^{23}$ In the $\mathrm{ab}$ initio results the systems were described using complete active space self-consistent field (CASSCF) wave functions; ${ }^{40}$ the calculations were performed using MOLCAS 3. ${ }^{41}$ Since 
TABLE 1: Comparison of INDO and ab Initio Results for $H_{\mathrm{ab}}$ for $\mathrm{Zn}_{2}\left(\mathrm{H}_{2} \mathrm{O}\right)_{n}{ }^{+}$in Idealized Water Geometries ${ }^{a}$

\begin{tabular}{|c|c|c|c|c|c|c|c|c|c|}
\hline geometry $^{b}$ & $R_{\mathrm{ZnZn}}{ }_{\text {init } c}$ & $\Delta r^{d}$ & $n^{e}$ & $\beta^{\text {INDO }}$ & $\beta^{a b}$ initio & $A^{\mathrm{INDO}}$ & $A^{a b \text { initio }}$ & $H_{\mathrm{ab}}{ }^{\operatorname{INDO} f}$ & $H_{\mathrm{ab}}$ ab initio $f$ \\
\hline$C_{2 v}$ & 6 & 2.8 & 4 & 1.40 & 1.39 & 11.6 & 11.3 & 236 & 183 \\
\hline $\mathrm{OH}$ & 6 & 2.8 & 4 & 1.07 & 1.24 & 10.8 & 11.1 & 437 & 270 \\
\hline perp & 6 & 2.8 & 4 & 1.68 & 1.39 & 12.3 & 11.2 & 133 & 166 \\
\hline$C_{2 v}$ & 8 & 2.8 & 4 & 1.31 & 1.38 & 10.3 & 10.5 & 25.6 & 20.6 \\
\hline $\mathrm{OH}$ & 8 & 2.8 & 4 & 1.00 & 1.25 & 9.3 & 10.1 & 48.7 & 28.2 \\
\hline perp & 8 & 2.8 & 4 & 1.53 & 1.36 & 11.0 & 10.3 & 15.0 & 19.7 \\
\hline$C_{2 v}$ & 8 & 3.0 & 4 & 1.50 & 1.46 & 11.1 & 10.8 & 16.8 & 15.8 \\
\hline $\mathrm{OH}$ & 8 & 3.0 & 4 & 1.19 & 1.34 & 10.1 & 10.4 & 33.2 & 21.7 \\
\hline perp & 8 & 3.0 & 4 & 1.75 & & 11.8 & & 8.45 & \\
\hline
\end{tabular}

${ }^{a}$ Methods described in Sections 2.2 and 2.3, $\beta\left(\AA^{-1}\right)$ and $A$ from fits of data to exponential form discussed in section 3 , with $H_{\mathrm{ab}}$ in $\mathrm{cm}^{-1}$. ${ }^{b}$ Geometries for intervening water, defined in refs 23 and 46. ${ }^{c} \mathrm{Zn}-\mathrm{Zn}$ distance for one intervening water, in angstroms. ${ }^{d}$ Assumed water diameter, in angstroms. ${ }^{e}$ Maximum number of sequential waters considered. ${ }^{f}$ Value of $H_{\mathrm{ab}}\left(\mathrm{cm}^{-1}\right)$ with two waters present.

more than one state was sought (in order to describe the initial and final states in the et process) the state-averaged CASSCF ${ }^{40}$ (SA/CASSCF) method was used here. The SA/CASSCF wave functions are denoted $\mathrm{m} / n$ 2SA/CASSCF, where $m$ and $n$ indicate the number of active electrons and orbitals, respectively, and 2SA/CASSCF indicates that two states were used in the state-averaging process. The calculations for $\mathrm{Zn}, \mathrm{Mg}$, or $\mathrm{Be}$, as $\mathrm{M}$ were based on 3/2 2SA/CASSCF and the calculations for $\mathrm{Li}$ or $\mathrm{Na}$ as $\mathrm{M}$ used $1 / 2$ 2SA/CASSCF wave functions.

The $\mathrm{Zn}$ basis set was built upon the Wachters $(14 \mathrm{~s}, 9 \mathrm{p}, 5 \mathrm{~d})$ basis ${ }^{42}$ contracted using a Raffenetti scheme ${ }^{43}$ based on the coefficients provided in ref 42 . This yields four s functions, two $\mathrm{p}$ functions, and one $\mathrm{d}$ function. The two most diffuse $\mathrm{s}$ basis functions and the most diffuse $\mathrm{p}$ and $\mathrm{d}$ functions of the original basis set were also added as additional uncontracted functions. Finally, diffuse s $(0.3960,0.015), \mathrm{p}(0.310,0.120$, $0.047,0.018)$, and $\mathrm{d}(0.155)$ functions were added to the basis. The ANO basis sets of Widmark and co-workers ${ }^{44}$ were used for $\operatorname{Li}[14 \mathrm{~s}, 9 \mathrm{p}, 4 \mathrm{~d}, 3 \mathrm{f} / 5 \mathrm{~s}, 3 \mathrm{p}, 2 \mathrm{~d}], \quad \mathrm{Be}[14 \mathrm{~s}, 9 \mathrm{p}, 4 \mathrm{~d}, 3 \mathrm{f} / 5 \mathrm{~s}, 3 \mathrm{p}, 2 \mathrm{~d}]$, $\mathrm{Na}[17 \mathrm{~s}, 12 \mathrm{p}, 5 \mathrm{~d}, 4 \mathrm{f} / 6 \mathrm{~s}, 4 \mathrm{p}, 2 \mathrm{~d}]$, and $\mathrm{Mg}[17 \mathrm{~s}, 12 \mathrm{p}, 5 \mathrm{~d}, 4 \mathrm{f} / 6 \mathrm{~s}, 4 \mathrm{p}, 2 \mathrm{~d}]$. In the calculations reported in Tables 1, 2, and 6, the water molecules were assigned their experimental equilibrium structures $^{45}$ (water: $R_{\mathrm{OH}}=0.957 \AA, \angle=104.5^{\circ}$ ). For water the ANO basis sets of Widmark and co-workers ${ }^{44}$ were used, having a primitive basis set for $\mathrm{O}$ of the form $(14 \mathrm{~s}, 9 \mathrm{p}, 4 \mathrm{~d})$ and a primitive set for $\mathrm{H}$ of the form $(8 \mathrm{~s}, 4 \mathrm{p})$. The $(4 \mathrm{~s}, 2 \mathrm{p})$ ANO contraction was used for $\mathrm{O}$ and the $(2 \mathrm{~s})$ ANO contraction was used for $\mathrm{H}$.

The basis sets used have been calibrated in a previous study ${ }^{23}$ and have been shown to be accurate to within $10-20 \%$ for the systems examined here, relative to results obtained from expanded basis sets.

\section{Results}

(a) $\mathbf{Z n}_{2}{ }^{+}$. The results for $\ln \left|H_{\mathrm{ab}}\right|$ vs $R_{\mathrm{ZnZn}}$ for solvated $\mathrm{Zn}_{2}{ }^{+}$ are shown in Figure 1. The results are a composite of $H_{\mathrm{ab}}$ from time slices for three trajectories, as discussed in section 2, using INDO CI wave functions and the GMH analysis to obtain $H_{\mathrm{ab}}$. Under the assumption that $H_{\mathrm{ab}}$ decays essentially exponentially with distance, the functional form $\ln \left|H_{\mathrm{ab}}\right|=-(\beta / 2) R_{\mathrm{ZnZn}}+A$ was fit to the data, thus the value of $\beta$ obtained is that appropriate to the decay of $\left|H_{\mathrm{ab}}\right|^{2}$. The fit yields a value of $\beta$ of $1.96 \pm 0.06 \AA^{-1}$ with a correlation coefficient of 0.95 . Also included in Figure 1 is $\ln \left|H_{\mathrm{ab}}\right|$ vs $R_{\mathrm{ZnZn}}$ for $\mathrm{Zn}_{2}{ }^{+}$with no waters present. The $\beta$ value obtained in this case is $3.57 \AA^{-1}$.

The values of $H_{\mathrm{ab}}$ are for $R_{\mathrm{ZnZn}}$ between 6 and $14 \AA$, which corresponds to approximately a range of one to three water diameters between the $\mathrm{Zn}$. If one fits over a smaller range of $R_{\mathrm{ZnZn}}$ the value of $\beta$ is relatively constant $(2.4$ for $6-10 \AA$, 1.8 for $9-13 \AA$ ).
While the decay with distance is relatively uniform over the whole range of distances examined, we obtain a substantial variation in $\ln \left|H_{\mathrm{ab}}\right|$ values between 12 and $14 \AA$. The actual spread in $H_{\mathrm{ab}}$ over this range is about $2 \mathrm{~cm}^{-1}$ (whereas the spread at $7 \AA$ is about $100 \mathrm{~cm}^{-1}$ ), but since the values of $H_{\mathrm{ab}}$ can be so small at this distance, the modest change in magnitude translates into a large variation in $\ln \left|H_{\mathrm{ab}}\right|$. In one trajectory that led to values of $R_{\mathrm{ZnZn}}$ between 13 and $14 \AA$, the $H_{\mathrm{ab}}$ values start near $0.2 \mathrm{~cm}^{-1}$, increase to about $1.4 \mathrm{~cm}^{-1}$, and then decrease again to $0.2 \mathrm{~cm}^{-1}$. There is no correlation of $H_{\mathrm{ab}}$ with $R_{\mathrm{ZnZn}}$ over this small range, but there is a correlation with the position of a single water that moves in to and out of the $\mathrm{Zn}-$ $\mathrm{Zn}$ line of centers, near one $\mathrm{Zn}$. There is also a considerable increase in the adiabatic state energy (up to $12000 \mathrm{~cm}^{-1}$ ) associated with this motion, which may account for a factor of about 1.5 change in $H_{\mathrm{ab}}$ due to non-Condon effects (see below), but the remainder of the change is likely due to specific superexchange effects that are maximized in certain geometries, e.g. those with waters directly between the $\mathrm{Zn}$ atoms. In addition, the variation in what would amount to an "average value" for $H_{\mathrm{ab}}$ at large distances is somewhat sensitive to the trajectory examined. The use of data for a trajectory with, on average, lower values of $H_{\mathrm{ab}}$ at large distances led to a value for $\beta$ (fit over $7-13 \AA$ ) of $2.34 \AA^{-1}$. As data was accumulated from the other two trajectories, having larger average values of $H_{\mathrm{ab}}$ in this distance range, $\beta$ decreased to the value of Figure 1 (1.96 $\left.\AA^{-1}\right)$.

To calibrate INDO for evaluation of $H_{\mathrm{ab}}$ we have performed comparison calculations on $\mathrm{Zn}_{2}\left(\mathrm{H}_{2} \mathrm{O}\right)_{n}{ }^{+}$clusters using idealized geometries. Since the first peak in the radial distribution function in our simulations occurs at approximately $2.8 \AA$ we have used values of 2.8 and $3.0 \AA$ for the water-water separation in the model calculations, with three idealized geometries defined in our previous ab initio studies on these systems. ${ }^{23,46}$ In Table 1 it is seen that the ab initio and INDO results are in generally good agreement, both for the $\beta$ values obtained and the values of $H_{\mathrm{ab}}$ themselves. The range of $\beta$ values is somewhat greater when INDO wave functions are used, but the $\beta$ 's are of similar size. Below we make limited comparisons of $a b$ initio and INDO $H_{\text {ab }}$ values for $\mathrm{Zn}_{2}\left(\mathrm{H}_{2} \mathrm{O}\right)_{n}{ }^{+}$geometries obtained from the simulations, and we find that in these cases the ab initio results lead to somewhat smaller values of $\beta$ for the subset of geometries examined.

One potential objection to the relevance of the above results for thermal et is that the $H_{\mathrm{ab}}$ values are not obtained at the crossing point between donor and acceptor surfaces and that the lack of near-degeneracy has a serious effect on the values of $H_{\mathrm{ab}}$ quoted. To investigate this possibility we have again chosen a series of model systems of the type $\mathrm{Zn}_{2}\left(\mathrm{H}_{2} \mathrm{O}\right)_{n}{ }^{+}$, using waters external to the $\mathrm{Zn}-\mathrm{Zn}$ line of centers to alter the donor 
TABLE 2: Non-Condon Effects on $\boldsymbol{H}_{\mathrm{ab}}$ for $\mathrm{Zn}_{2}\left(\mathrm{H}_{2} \mathrm{O}\right)_{1,2}{ }^{+a}$

\begin{tabular}{ccccrc}
\hline $\begin{array}{c}R_{\mathrm{ZnZn}^{-}} \\
(\AA)\end{array}$ & $\begin{array}{c}R_{\mathrm{Zn}-\text { Oout }} \\
(\AA)\end{array}$ & $\begin{array}{c}R_{\mathrm{Zn}^{-O_{i n}}} \\
(\AA)\end{array}$ & $\begin{array}{c}\text { no. of inner } \\
\mathrm{H}_{2} \mathrm{O} \text { molecules }\end{array}$ & $\begin{array}{c}\Delta E_{\text {adiabatic }^{-}} \\
\left(\mathrm{cm}^{-1}\right)\end{array}$ & $\begin{array}{c}H_{\mathrm{ab}^{-}} \\
\left(\mathrm{cm}^{-1}\right)\end{array}$ \\
\hline 5 & 2 & & 0 & 16880 & 3101 \\
5 & 2.5 & & 0 & 11690 & 2572 \\
5 & 3 & & 0 & 6609 & 2205 \\
5 & $\infty$ & & 0 & 4036 & 2018 \\
7 & 2 & & 0 & 18230 & 115.8 \\
7 & 2.5 & & 0 & 11883 & 96.5 \\
7 & 3 & & 0 & 5522 & 82.7 \\
7 & $\infty$ & & 1 & 151 & 75.5 \\
6 & 2 & 3 & 1 & 14570 & 2699 \\
6 & 2.5 & 3 & 1 & 46214 & 2231 \\
6 & 3 & 3 & 1 & 4000 & 1724 \\
6 & $\infty$ & 3 & 1 & 21270 & 704 \\
7 & 2 & 3 & 1 & 14780 & 568 \\
7 & 2.5 & 3 & 1 & 8622 & 478 \\
7 & 3 & 3 & & 3601 & 431 \\
7 & $\infty$ & 3 & & &
\end{tabular}

${ }^{a}$ Calculations were performed with two $\mathrm{Zn}$ at $R_{\mathrm{ZnZn}}$, with a single water external to the $\mathrm{Zn}-\mathrm{Zn}$ line of centers, in the $C_{2 v}$ orientation nearest the left-hand $\mathrm{Zn}$, with the $\mathrm{O}$ atom at a distance of $R_{\mathrm{Zn}-\mathrm{Oout}}$ from the $\mathrm{Zn}$ ( $\mathrm{H}$ atoms pointed away from the left-hand $\mathrm{Zn}$ ). When a water is present along the $\mathrm{Zn}-\mathrm{Zn}$ line of centers, it too is in the $C_{2 v}$ orientation with the $\mathrm{O}$ atom directed at the right-hand $\mathrm{Zn}$, at a distance of $R_{\mathrm{ZnOin}}$ from the left-hand $\mathrm{Zn}$. $\Delta E_{\text {adiabatic }}$ is the difference in energy of the two adiabatic states used in the GMH analysis. INDO wave functions and analysis for $H_{\mathrm{ab}}$ as described in section 2.2.

and acceptor geometries. In previous studies at the ab initio level ${ }^{23,36}$ these external waters have been shown to significantly affect the donor-acceptor energy spacing, but to have little effect on the electronic coupling element. The results in Table 2 address this question at the INDO level, for a range of $\mathrm{Zn}-$ water distances.

In particular, in Table 2 we examine $H_{\mathrm{ab}}$ between the two $\mathrm{Zn}$ atoms with and without intervening water, with the external water in the $C_{2 v}$ orientation at various $\mathrm{Zn}-\mathrm{O}$ distances. It is seen that the external water can have a nonnegligible effect, raising the electronic coupling element by about $50 \%$ when the external water $\mathrm{Zn}-\mathrm{O}$ distance is $2 \AA$. This $50 \%$ increase in $H_{\mathrm{ab}}$ is accompanied by a nearly $2 \mathrm{eV}$ difference in adiabatic state energies. The bulk of the variation in $H_{\mathrm{ab}}$ occurs for $\mathrm{R}_{\mathrm{ZnOout}}$ distances less than $3 \AA$, while for values greater than $3 \AA$ the variation is quite modest (i.e., there is a small change in $H_{\mathrm{ab}}$ for $\mathrm{R}_{\mathrm{ZnOout}}$ in the range of $3 \AA$ to $\infty$ ). For the time slices used in the data for Figure 1 our closest $\mathrm{Zn}-\mathrm{O}$ distances are in the range of $2.9 \AA$, while most are $3 \AA$ or greater. The smallest $\mathrm{Zn}-\mathrm{H}$ distance is about $2.2 \AA$, which in test calculations similar to those of Table 2 yields variations in $H_{\mathrm{ab}}$ comparable to those with $\mathrm{O}$ atoms at $3 \AA$. Furthermore, there is no discernible correlation between energy gap and the size of $H_{\mathrm{ab}}$ at a given distance in the results of Figure 1. Thus, for the simulations we have performed it appears that the non-Condon effects we observe lead to variations of $H_{\mathrm{ab}}$ generally on the order of 10$20 \%$ which, while nonzero, are small enough not to alter our value for $\beta$ significantly.

The MD simulations reported above used a flexible water model, leading to a range of water geometries in the time slices examined. The average $R_{\mathrm{OH}}$ values was approximately 0.976 $\pm 0.025 \AA$, while the average $\angle_{\mathrm{HOH}}$ was $99 \pm 5^{\circ}$. To assess the effects of these variations on $H_{\mathrm{ab}}$ we performed model calculations with a variety of water geometries (Table 3). The $\mathrm{Zn}-$ $\mathrm{Zn}$ distance was fixed at $6 \AA$, with a single intervening water in the $C_{2 v}$ geometry ${ }^{46}$ with the $\mathrm{O}$ atom $3 \AA$ from either $\mathrm{Zn}$. The water geometry (bond lengths and angle) was varied with the $\mathrm{Zn}$ and $\mathrm{O}$ atoms fixed, and $H_{\mathrm{ab}}$ was calculated. The results of Table 3 indicate that these geometry variations lead to ap-
TABLE 3: $H_{a b}$ for $\mathrm{Zn}_{2} \mathrm{H}_{2} \mathrm{O}^{+}$as a Function of Water Geometry ${ }^{a}$

\begin{tabular}{ccccc}
\hline$R_{\mathrm{OH} 1}(\AA)$ & $R_{\mathrm{OH} 2}(\AA)$ & $\angle \mathrm{HOH}($ degrees $)$ & $\Delta E\left(\mathrm{~cm}^{-1}\right)$ & $H_{\mathrm{ab}}\left(\mathrm{cm}^{-1}\right)$ \\
\hline 0.957 & 0.957 & 104.53 & 4000 & 1724 \\
0.907 & 0.907 & 104.53 & 3919 & 1618 \\
1.007 & 1.007 & 104.53 & 4129 & 1845 \\
1.050 & 1.050 & 104.53 & 4285 & 1964 \\
0.957 & 0.957 & 95.0 & 4101 & 1768 \\
0.957 & 0.957 & 115.0 & 3911 & 1684 \\
1.007 & 0.907 & 104.53 & 4011 & 1730
\end{tabular}

${ }^{a}$ The two $\mathrm{Zn}$ atoms are $6 \AA$ apart, the water is between the two $\mathrm{Zn}$ atoms with the $\mathrm{O}$ atom midway between the two $\mathrm{Zn}$, and the water is in the $C_{2 v}$ orientation. ${ }^{46}$ INDO wave functions and analysis for $H_{\mathrm{ab}}$ as described in section 2.2 .

proximately $10 \%$ changes in $H_{\mathrm{ab}}$. Using the water geometry $R_{\mathrm{OH}}$ $=1.05 \AA$ and $\angle \mathrm{HOH}=104.53^{\circ}$ and an assumed water diameter of $2.8 \AA$, we repeated the calculations of Table 1 for the successive addition of intervening $C_{2 v}$ waters. For $n_{\mathrm{H} 2 \mathrm{O}}=1-4$ the $\beta$ value obtained with this elongated water was $1.31 \AA^{-1}$ (cf. $1.4 \AA^{-1}$ with waters in the gas-phase equilibrium geometry). Thus, while water geometry can play a small quantitative role in determining the size of $H_{\mathrm{ab}}$ or $\beta$, it does not appear to play a qualitative role. Results of calculations similar to those in Figure 1, obtained using a rigid water model (not shown) yield similar values for $\beta$, further supporting the assertion that internal water motion has little effect on the value of $\beta$ we obtain.

We have attempted to analyze several of the time slices used in Figure 1, to determine if there is a subset of waters from those chosen in our selection procedure that is predominantly responsible for the solvent-enhanced electronic coupling elements we observed in our studies. We have chosen four time slices, having $\mathrm{Zn}-\mathrm{Zn}$ distances of 7.656, 8.470, 9.476, and $10.341 \AA$, yielding 16, 21, 30, and 42 waters, respectively, after our standard truncation procedure. These data points fall close to the line of best fit (the $\beta$ value based on these four points is $2.28 \AA^{-1}$ ). We then systematically removed waters, using a sphere centered at the $\mathrm{Zn}-\mathrm{Zn}$ midpoint, with decreasing radius, such that at each stage another 4 waters were removed, until we reached eight waters, after which single waters were removed. The results for $H_{\mathrm{ab}}$ as a function of number of waters are shown in Figure 2, and the results for the adiabatic energy differences are shown in Figure 3 (note the $x$ and $y$ axis scales are different in the various graphs). It is seen that the dominant contribution to $H_{\mathrm{ab}}$ arises from a few waters, and the number of important waters correlates roughly with $\mathrm{Zn}-\mathrm{Zn}$ distance, suggesting one is seeing effects of one or more solvent diameters between the $\mathrm{Zn}$. While this is clearly a small subset of the time slices examined, it nevertheless suggests that the superexchange effects observed are local, and comprehensible based on the presence of a few waters. In Figure 4 we show the geometry used for the time slice corresponding to $R_{\mathrm{ZnZn}}=9.476 \AA$. All the waters used in the analysis for these data point in Figure 1 are shown, with those determined to be the dominant contributors in the analysis of Figures 2 and 3 highlighted. It is seen that these waters occupy positions between the $\mathrm{Zn}$ atoms as one might expect, based on the assumption that those along the most direct route from one $\mathrm{Zn}$ to the next should yield the dominant contribution to the coupling.

The results of Table 1 compared ab initio and INDO results for idealized geometries as the number of waters was increased. In Table 4 we present data that compares ab initio and INDO $H_{\mathrm{ab}}$ values for the four time slices examined in Figures 2 and 3. While in the ab initio calculations we would like to have included the full number of waters used in Figure 1 at each time slice, this is not feasible computationally. At each distance 

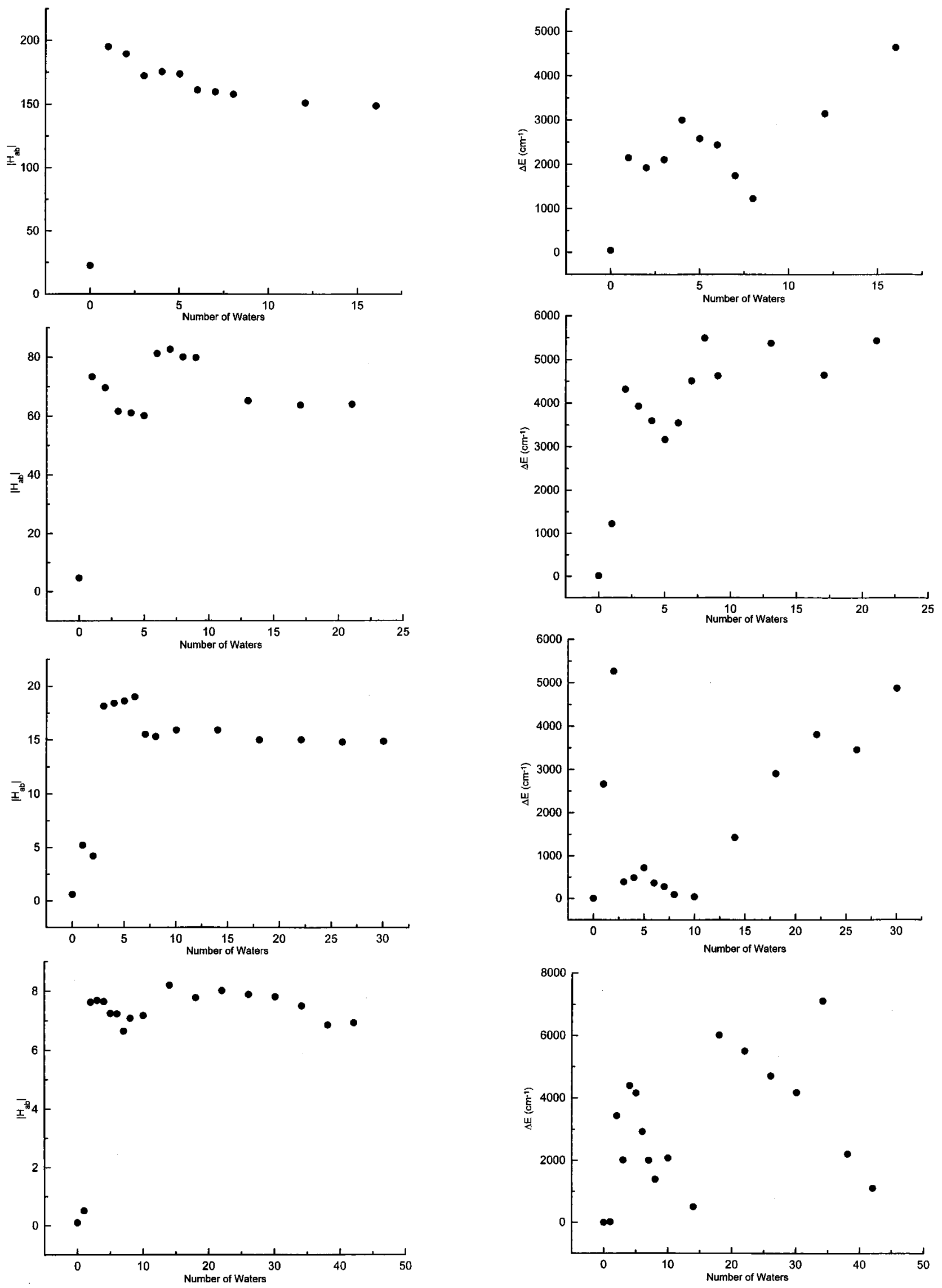

Figure 2. $\left|H_{\mathrm{ab}}\right|$ for $\mathrm{Zn}_{2}{ }^{+}$et in water as a function of number of waters for four time slices. The waters are sequentially removed on the basis of their distance from the midpoint of the $\mathrm{Zn}-\mathrm{Zn}$ line of centers. (a) $R_{\mathrm{ZnZn}}=7.656 \AA$, (b) $R_{\mathrm{ZnZn}}=8.470 \AA$, (c) $R_{\mathrm{ZnZn}}=9.476 \AA$, and (d) $R_{\mathrm{ZnZn}}=10.431 \AA$

Figure 3. $\Delta E_{\text {adiabatic }}$ for $\mathrm{Zn}_{2}{ }^{+}$in water as a function of number of waters for four time slices. The waters are sequentially removed on the basis of their distance from the midpoint of the $\mathrm{Zn}-\mathrm{Zn}$ line of centers. (a) $R_{\mathrm{ZnZn}}=7.656 \AA$, (b) $R_{\mathrm{ZnZn}}=8.470 \AA$, (c) $R_{\mathrm{ZnZn}}=9.476 \AA$, (d) $R_{\mathrm{ZnZn}}$ $=10.431 \AA$ 


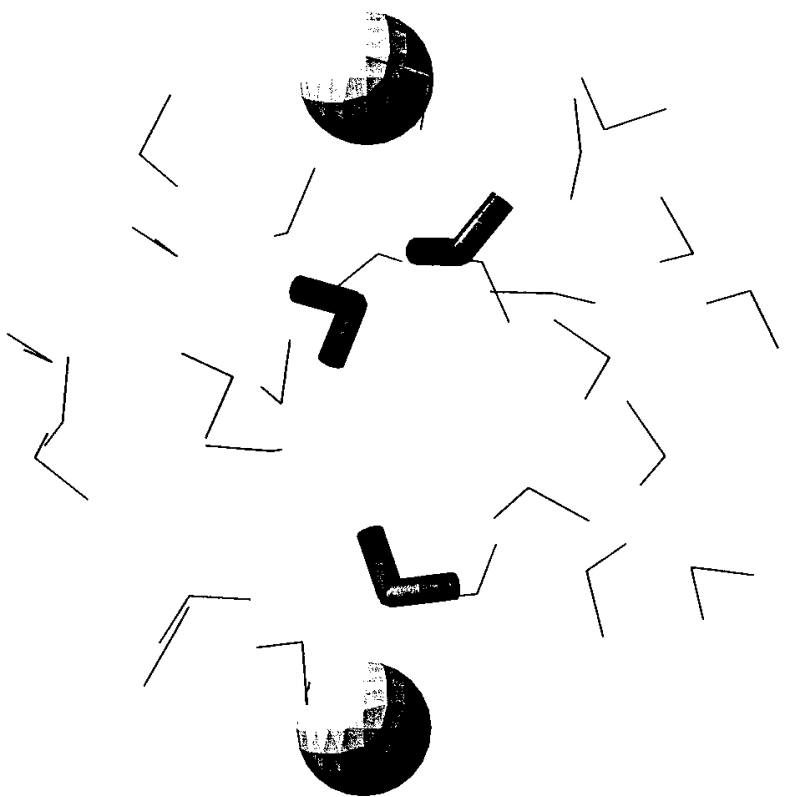

Figure 4. $\mathrm{Zn}_{2}{ }^{+}$and all waters included in the analysis for Figure 1 for this time slice (with $R_{\mathrm{ZnZn}}=9.476 \AA$ ). The highlighted waters are those determined to be important to the value of $H_{\mathrm{ab}}$ at this distance, based on the results of Figure 2c.

TABLE 4: Comparison of ab Initio and INDO $\boldsymbol{H}_{\mathrm{ab}}$ Values for $\mathrm{Zn}_{2}\left(\mathrm{H}_{2} \mathrm{O}\right)_{n}{ }^{+}$for Several Time Slices ${ }^{a}$

\begin{tabular}{rrrr}
\hline$R_{\text {ZnZn }}(\AA)$ & $n^{b}$ & $H_{\mathrm{ab}^{\mathrm{INDO}} c}$ & $H_{\mathrm{ab}}{ }^{\text {ab initio } c}$ \\
\hline 7.656 & 16 & 148.9 & \\
8.470 & 21 & 63.9 & \\
9.476 & 30 & 14.9 & \\
10.431 & 42 & 6.9 & \\
7.656 & 3 & 172.3 & 200.3 \\
8.470 & 3 & 61.6 & 62.2 \\
9.476 & 3 & 18.1 & 29.8 \\
10.431 & 3 & 7.7 & 10.1 \\
7.656 & 5 & 173.8 & 182.4 \\
8.470 & 5 & 60.1 & 60.7 \\
9.476 & 5 & 18.6 & 32.6 \\
10.431 & 5 & 7.2 & 11.2
\end{tabular}

${ }^{a}$ The time slices chosen were those used in Figures 2 and 3. All $H_{\mathrm{ab}}$ are in $\mathrm{cm}^{-1} .{ }^{b}$ The value of $n$ is the number of waters included in the calculation of $H_{\mathrm{ab}}$; values not equal to 3 or 5 indicate the full number of waters used for this $R_{\mathrm{ZnZn}}$ in the data of Figure $1 .{ }^{c}$ INDO and ab initio $H_{\mathrm{ab}}$ values at the given geometry with the number of waters indicated. Based on the four points shown: $\beta^{\mathrm{INDO}}$ (full set of waters) $=2.28 \AA^{-1}, \beta^{\mathrm{INDO}}$ (3 waters) $=2.26 \AA^{-1}, \beta^{\text {abinitio }}(3$ waters $)=2.07$ $\AA^{-1}, \beta^{\mathrm{INDO}}(5$ waters $)=2.31 \AA^{-1}, \beta^{\text {abinitio }}(5$ waters $)=1.88 \AA^{-1}$.

we have thus chosen to use the geometries obtained after the truncation to three waters and to five waters. It is seen from Figure 2 that for three waters the INDO $H_{\mathrm{ab}}$ at each time slice is similar to the value obtained in our standard truncation procedure. The $\beta$ values based on the four three-water points are $\beta^{\text {INDO }}=2.26 \AA^{-1}$ and $\beta^{\text {ab initio }}=2.07 \AA^{-1}$, while those for the four five-water points are $\beta^{\mathrm{INDO}}=2.31 \AA^{-1}$ and $\beta^{\mathrm{ab} \text { initio }}=$ $1.88 \AA^{-1}$. We were unable to extend the ab initio calculations to larger number of waters in this basis set due to disk storage limitations, but using a somewhat smaller basis we obtained similar behavior for three and five waters, and showed that extension to seven waters at each geometry lead to a $\beta^{\text {ab initio }}$ only $0.03 \AA^{-1}$ less than that for the five water case. It appears that the ab initio values lead to somewhat slower decay and are a bit more sensitive to changes in the number of waters included in the calculation, and that, on the basis of these comparisons, $\beta^{\text {ab initio }}$, based on all the time slices in Figure 1, would be in the range of 1.5 to $1.8 \AA^{-1}$.
TABLE 5: $\beta$ Computed Based on Ten Time Slices for $\mathrm{M}_{2}^{+}$ with Water, $\mathrm{M}=\mathrm{Be}, \mathrm{Mg}, \mathrm{Zn}, \mathrm{Cu}^{a}$

\begin{tabular}{cccc}
\hline $\mathrm{M}_{2}{ }^{+}$ & $\mathrm{IP}(\mathrm{eV})^{b}$ & $\beta^{\mathrm{INDO}}\left(\mathrm{M}_{2}{ }^{+}\right)$ & $\beta^{\text {INDO }}\left(\mathrm{M}_{2}{ }^{+}\right.$with water $)$ \\
\hline $\mathrm{Zn}_{2}{ }^{+}$ & 9.36 & 3.58 & 2.02 \\
$\mathrm{Be}_{2}{ }^{+}$ & 9.33 & 2.70 & 1.89 \\
$\mathrm{Mg}_{2}{ }^{+}$ & 8.11 & 2.70 & 1.94 \\
$\mathrm{Cu}_{2}{ }^{+}$ & 7.76 & 3.42 & 1.99
\end{tabular}

${ }^{a}$ See text for details on selection of time slices. $\beta$ in $\AA^{-1} .{ }^{b}$ IP based on orbital energy using Koopmans' theorem.

(b) Other $\mathrm{M}_{2}{ }^{+}$Systems. To examine the D-A orbital energy sensitivity of the results presented above for $\mathrm{Zn}_{2}{ }^{+}$, we have performed a series of calculations using INDO and ab initio wave functions with $\mathrm{Li}, \mathrm{Be}, \mathrm{Na}, \mathrm{Mg}$, or $\mathrm{Cu}$ substituted for $\mathrm{Zn}$ as $\mathrm{D}$ and $\mathrm{A}$.

In the first set of calculations we selected 10 of the time slices used in Figure 1 which had $H_{\mathrm{ab}}$ values for solvated $\mathrm{Zn}_{2}{ }^{+}$lying on or near the best fit line, spanning $\mathrm{Zn}-\mathrm{Zn}$ distances of from 8 to $13 \AA$. In place of each of the two $\mathrm{Zn}$ atoms in a given time slice we then substituted either $\mathrm{Be}, \mathrm{Mg}$, or $\mathrm{Cu}$ and recalculated $H_{\mathrm{ab}}$ with the new donor and acceptor at each time slice. As a means of comparing the tunneling energies in these cases, one can use the orbital energies of the atoms which, for INDO/ RHF were $\mathrm{Zn}(-9.36 \mathrm{eV}), \mathrm{Be}(-9.33 \mathrm{eV}), \mathrm{Mg}(-8.11 \mathrm{eV})$, and $\mathrm{Cu}(-7.76 \mathrm{eV})$. Thus, these calculations allow for a $1.6 \mathrm{eV}$ variation in $\mathrm{D}-\mathrm{A}$ orbital energy relative to the $\mathrm{HOMO}$ of water $(-12.8 \mathrm{eV}$ INDO/RHF).

In Table 5 we present $\beta$ values based on the 10 time slices, for each of the $\mathrm{D}-\mathrm{A}$ pairs discussed above. In addition we present $\beta$ for "bare" (no solvent) $\mathrm{M}_{2}{ }^{+}$. It is seen that while there are significant variations in $\beta$ for the bare $\mathrm{M}_{2}{ }^{+}$(controlled largely by the INDO orbital exponent) there is, in fact, only modest variation in $\beta$ with water present. A simple McConnell model which assumes hole transfer is the predomiinant mechanism (consistent with previous ab initio results for $\mathrm{Zn}_{2}{ }^{+}-$water systems) and only uses the water HOMO for superexchange (inferring the water-water coupling element from the solvated $\mathrm{Zn}_{2}{ }^{+}$data) would predict a variation in $\beta$ of approximately 0.3 $\AA^{-1}$. Using instead the HOMO-1 of water $(-14.7 \mathrm{eV})$ in an analogous model yields a variation in $\beta$ of $0.2 \AA^{-1}$, similar in size to what we observe in the full calculations. However, the predicted $\beta$ values in this model for $\mathrm{Mg}$ and $\mathrm{Cu}$ would be larger than those for $\mathrm{Zn}$, whereas the calculated values for the solvated systems yield slightly smaller values of $\beta$ (Table 5). This may indicate the contribution of particle transfer as well as hole transfer to $H_{\mathrm{ab}}{ }^{14}$

$\mathrm{Ab}$ Initio results for $\beta$ are presented in Table 6 using multiple waters in idealized geometries $\left(C_{2}, \mathrm{OH}\right)$ and $\mathrm{M}=\mathrm{Li}, \mathrm{Be}, \mathrm{Na}$, $\mathrm{Mg}$, or $\mathrm{Zn}$. These calculations are similar to the ab initio results presented in Table 1, except that the $\mathrm{D}-\mathrm{A}$ pair is changed (the $\mathrm{Zn}$ results of Table 1 are reproduced here for ease of comparison). While the IP values range over almost $3.5 \mathrm{eV}$ in this series, it is seen that the $\beta$ values with water present are all quite close to those obtained with $\mathrm{Zn}_{2}{ }^{+}$as the $\mathrm{D}-\mathrm{A}$ pair. On the other hand, the bare $\mathrm{M}_{2}{ }^{+}$(no water) values for $\beta$ span a much greater range, consistent with the range of IP values in this series.

\section{Discussion}

The results presented above suggest that water can significantly enhance the electronic coupling between a donor and acceptor in aqueous et processes, contrary to what has been observed in a number of previous studies of the electronic coupling element in water. ${ }^{26,27}$ In addition, the value of $\beta$ is 
TABLE 6: Comparison of ab initio $\beta$ Values for Various $\mathrm{M}_{2}{ }^{+}(\mathrm{M}=\mathrm{Li}, \mathrm{Be}, \mathrm{Na}, \mathrm{Mg}, \mathrm{Zn})$ for Idealized Water Geometries

\begin{tabular}{cccccc}
\hline $\mathrm{M}$ & geometry $^{b}$ & $R_{\mathrm{MM}}{ }^{\text {init } c}$ & $\Delta r^{d}$ & $\mathrm{n}^{\mathrm{e}}$ & $\beta^{\text {water }}$ \\
\hline $\mathrm{Zn}^{f}$ & $C_{2 v}$ & 8 & 2.8 & 4 & 1.38 \\
$\mathrm{Zn}^{f}$ & $\mathrm{OH}$ & 8 & 2.8 & 4 & 1.25 \\
$\mathrm{Be}$ & $C_{2 v}$ & 8 & 2.8 & 4 & 1.35 \\
$\mathrm{Be}$ & $\mathrm{OH}$ & 8 & 2.8 & 4 & 1.23 \\
$\mathrm{Li}^{f}$ & $C_{2 v}$ & 8 & 2.8 & 4 & 1.34 \\
$\mathrm{Li}$ & $\mathrm{OH}$ & 8 & 2.8 & 3 & 1.27 \\
$\mathrm{Na}$ & $C_{2 v}$ & 8 & 2.8 & 3 & 1.35 \\
$\mathrm{Mg}$ & $C_{2 v}$ & 8 & 2.8 & 4 & 1.41 \\
$\mathrm{Mg}$ & $\mathrm{OH}$ & 8 & 2.8 & 4 & 1.26
\end{tabular}

${ }^{a}$ Methods described in section 2.3, $\beta\left(\AA^{-1}\right)$. The Koopmans' IP values for $\mathrm{Zn}, \mathrm{Be}$, and $\mathrm{Mg}$ are $7.98,8.42$, and $6.88 \mathrm{eV}$, respectively. The IPs for $\mathrm{Li}$ and $\mathrm{Na}$, calculated as an energy difference between the neutral and the cation, are 5.3 and $4.95 \mathrm{eV}$, respectively. The $\beta$ values for these D-A pairs with no water present $\left(\AA^{-1}\right.$, fit over $R_{\mathrm{M}-\mathrm{M}}=5-10$ $\AA$ for all but $\mathrm{Zn}_{2}{ }^{+}$which was fit over $\left.R_{\mathrm{Zn}-\mathrm{Zn}}=6-10 \AA\right)$ are $2.71\left(\mathrm{Zn}_{2}{ }^{+}\right)$, $2.71\left(\mathrm{Be}_{2}{ }^{+}\right), 1.83\left(\mathrm{Li}_{2}{ }^{+}\right), 1.52\left(\mathrm{Na}_{2}{ }^{+}\right), 2.27\left(\mathrm{Mg}_{2}{ }^{+}\right) \cdot{ }^{b}$ Geometries for intervening water, defined in refs 23 and $46 .{ }^{c} \mathrm{M}-\mathrm{M}$ distance for one intervening water, in angstroms. ${ }^{d}$ Assumed water diameter, in angstroms. ${ }^{e}$ Maximum number of sequential waters considered. ${ }^{f}$ Results from ref 23 .

found to be weakly dependent on D-A orbital energy. Finally, we find that the value for $\beta$ obtained is somewhat larger than that found in organic glasses ${ }^{10-12}$ or that observed for covalently bonded donor and acceptor species. ${ }^{13,14}$ Note that our calculations are all-valence-electron calculations in the case of the INDO results or all-electron calculations in the ab initio case. Hence, our results include both hole- and particle-transfer contributions to $H_{\mathrm{ab}}$ unlike one-electron pseudopotential based treatments that can only explicitly treat hole transfer (see comments below).

We have performed a variety of similar simulations (yielding data akin to that in Figure 1) to address the sensitivity of the above results to the parameters used in the MD simulations. In simulations using a less accurate water model (first peak in the radial distribution function near $3.2 \AA$ ), using identical techniques for the calculation of $H_{\mathrm{ab}}$ we obtained a $\beta$ value of 2.0 $\AA^{-1}\left(R_{\mathrm{Zn}-\mathrm{Zn}}=7-12 \AA\right)$. In another set of test calculations we used the same water model as that of Figure 1, but used a $\mathrm{Zn}$ with radius of $1.5 \AA$. This model allowed closer approach of waters to the $\mathrm{Zn}$ atoms and tended to yield larger adiabatic state energy differences (on the order of $2 \mathrm{eV}$ ) in the INDO calculations. Nevertheless, the $H_{\mathrm{ab}}$ values were similar to those presented in Figure 1 at a given $R_{\mathrm{ZnZn}}$ and the value of $\beta$ was about $2.0 \AA^{-1}\left(R_{\mathrm{Zn}-\mathrm{Zn}}=7-10 \AA\right)$. Clearly, the results are not terribly sensitive to the details of the water structure at a given density, and small adjustments to the water model should not yield significantly altered $\beta$ values.

The present results indicate there is a substantial enhancement of $H_{\mathrm{ab}}$ due to the presence of intervening solvent. However, they also indicate that $\beta$ values extracted from model systems using idealized geometries (e.g., Table 1) will not be accurate representations of the values obtained in solution. The results based on INDO wave functions of Table 1 show that any of the idealized configurations chosen there yield $\beta$ values $0.3-$ $0.9 \AA^{-1}$ smaller than those obtained in Figure 1. The limited $\mathrm{ab}$ initio results for nonidealized geometries also yield $\beta$ greater than those found in the idealized cases. Since identical types of wave functions are used in both idealized and nonidealized geometries, it would appear that the predominant effect brought on by thermal motion is to diminish the average water-water coupling, and to lead to faster decay with distance than in the idealized geometries.
Given that the INDO $\beta$ values in Table 1 exhibit a greater spread than the ab initio values, one might suppose that thermal motion would have a greater effect on the INDO results and that, were the complete set of calculations for Figure 1 repeated using $\mathrm{ab}$ initio methods, $\beta$ would significantly decrease. For example, the ab initio $\beta$ for $\mathrm{Zn}_{2}{ }^{+}$with no waters present ${ }^{23}$ is $2.7 \AA^{-1}$, whereas for INDO the value is $3.57 \AA^{-1}$. Seeing that in water the INDO $\beta$ is lowered by $1.6 \AA^{-1}$ one might reason that water would lower the ab initio value a similar amount,

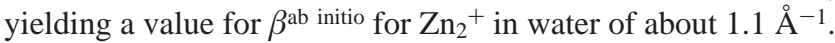
While it is conceivable that this might occur, we do not observe such a dramatic difference in the comparisons we have made for nonidealized geometries (Table 4). There it is seen that the ab initio $\beta$ value is somewhat lower than the INDO value (by up to $0.4 \AA^{-1}$ ), and appears to depend to a somewhat greater extent on the number of waters in the calculation of $H_{\mathrm{ab}}$. This last point is also consistent with the relative insensitivity of the ab initio $\beta$ values in the idealized geometries treated in Table 1. If this difference between the truncated INDO and ab initio calculations carried over to the full water calculations, were they possible at the ab initio level, one might expect $\beta^{\text {ab initio for }} \mathrm{Zn}_{2}{ }^{+}$ in the realm of $1.5-1.8 \AA^{-1}$. In addition, given the insensitity of $\beta$ to $\mathrm{D}-\mathrm{A}$ energy observed above in the series of test calculations, we would expect this value of $\beta$ for other $\mathrm{D}-\mathrm{A}$ pairs with orbital energies in the water HOMO-LUMO gap.

Our results are in reasonable agreement with Larsson's early study on the electronic coupling in water. ${ }^{22}$ He used a superexchange model and estimated the water-water coupling element from orientation-averaged ab initio calculations. Larsson found a significant enhancement of the electronic coupling at a given donor-acceptor distance with intervening water and his value of $\beta\left(2.4 \AA^{-1}\right)$ is similar to that which we obtain when we fit over the range of $6-10 \AA$ in Figure 1 . While our overall value for $\beta$ is somewhat lower than his, the reasonable agreement suggests that the Larsson model captures the essence of that which we observe in the present calculations.

As noted above, previous ab initio calculations ${ }^{23}$ suggested that water could significantly enhance the electronic coupling between a donor and acceptor, but due to the use of idealized geometries and limited numbers of water molecules, it was not clear whether the differences between the ab initio and oneelectron results (which suggested that water had little to no effect on the coupling ${ }^{26,27}$ ) were due to the neglect of surrounding waters in the ab initio case. Our results show this is not the case, even with larger numbers of waters the present calculations indicate that water is an effective superexchange medium. On the basis of these results, it is likely that the previous studies which are based on one-electron models (only treating the transferring electron, using pseudopotentials to model the donor, acceptor, and waters) neglect important superexchange pathways involving occupied water orbitals (hole transfer).

Of course, it is still possible that a number of other important effects have been neglected in the present calculations, and that the results obtained from them do not represent an accurate picture of superexchange effects in water. For example, Davis et al. ${ }^{47}$ have developed a model that examines the transition from the tunneling regime to the electron-hopping regime, and they are exploring this model for covalently linked donoracceptor species. Along these lines, it may be that long-range et in water is dominated by local hopping rather than direct $\mathrm{D}-\mathrm{A}$ tunneling, and if so, the present calculations cannot directly comment on superexchange coupling in water. Indeed, if the hopping involves sites reminiscent of solvated electrons, basis set calculations of the type used here will be unable to 
address such questions easily, since basis sets in conventional ab initio or semiempirical studies tend to be atom based, and will thus yield poor descriptions of solvent-trapped electrons. Due to the relatively weak water-water coupling and the fast vibrational and reorientational coordinates in water, the dephasing times may be short, which would tend to make the crossover to a hopping mechanism occur at shorter distances. However, the difference between the tunneling energy (approximately 9 $\mathrm{eV}$ ) and the estimated energy of the medium-localized electron (about $1 \mathrm{eV}$ ) is a good deal larger than that for the systems of Davis et al., suggesting that larger tunneling distances may be required before such effects are important in water.

Another possibility is that our results are not directly related to long-range tunneling in water since they do not explicitly treat inelastic tunneling events. Recent work by Stuchebrukhov and co-workers ${ }^{48,49}$ has shown the important contribution such effects can have for long range et, with particular emphasis on the inverted region. In the inverted region, inelastic events that result in medium vibrational excitation actually serve to increase the rate at large distances. In our case, far from the inverted region, one would expect similar events to lead to an overall decrease in rate for large distances. If they are important for our system, events of this kind would be expected to lead to larger effective values of $\beta$ than those which we report.

A third possibility that might lead to distinctly different values for $\beta$ would be that for large distance transfer the dominant contribution to the rate comes from infrequent solvent orientations leading to dramatically enhanced values for $H_{\mathrm{ab}}$. At short $\mathrm{R}$ the difference in $H_{\mathrm{ab}}$ obtained at particularly favorable configurations and the "average configuration" is not great, since a nonzero component of the coupling at short $R$ is expected to arise from direct transfer (i.e., superexchange pathways do not completely dominate). On the other hand, at large $R$, infrequent configurations that might lead to 3-5-fold increases in $H_{\mathrm{ab}}$ can yield ten- to 20 -fold increases in rate, and may in fact be the predominant long-distance pathways. Our results in the range of 13-14 $\AA$ are suggestive of this possibility, but more work needs to be done to quantify the frequency of such events in order to comment on their relevance to experimental situations. In a separate set of simulations using a less accurate water potential we have seen evidence for such configurations as well. In these simulations we held the $\mathrm{Zn}-\mathrm{Zn}$ distance fixed at 5, 6, 7 , 8 , or $9 \AA$, and allowed the surrounding water molecules to evolve at $300 \mathrm{~K}$. We found that the thermally averaged $H_{\mathrm{ab}}$ values at 8 and $9 \AA$ were essentially indistinguishable (one trajectory for each distance), and we attribute the lack of decay in $H_{\text {ab }}$ between 8 and $9 \AA$ to better water packing between $\mathrm{D}$ and $\mathrm{A}$ at the larger distance. The increased coupling due to an extra water along the $\mathrm{Zn}-\mathrm{Zn}$ line of centers may offset the increased distance between the two $\mathrm{Zn}$, leading to essentially no decay with distance. If one assumed that only the larger values of $H_{\mathrm{ab}}$ were relevant at large $R$ and refit the present data only using the points above the best fit line of Figure 1 beyond $10 \AA$, the value of $\beta$ obtained is $1.66 \AA^{-1}$ rather than $2.0 \AA^{-1}$. Our simulations only utilize a single donor-acceptor pair, and so the frequency of such occurrences is limited by their need to arise along the single $\mathrm{Zn}-\mathrm{Zn}$ distance. On the other hand, in experiments with randomly oriented donors and acceptors in glassy matrixes many more directions are sampled due to the presence of a range of acceptors, and thus it is possible that only the most favorable solvent configurations contribute at large distances, leading to a potentially smaller value for $\beta$. Longer simulations and more frequent sampling may be required to investigate this question in the future.
The value of $\beta$ is also expected to depend to some extent on the difference in energy between the $\mathrm{D}-\mathrm{A}$ orbitals and the occupied and virtual orbitals in water. With $\mathrm{Zn}_{2}{ }^{+}$as our D-A pair, the gas-phase IP is $8-9 \mathrm{eV}$. Variations of up to $3.5 \mathrm{eV}$ in orbital energy (ab initio calculations) yielded little change in $\beta$ for the results presented above, but it is expected that for $\mathrm{D}-\mathrm{A}$ energies nearer the HOMO or LUMO energy of water will lead to smaller values of $\beta$. Photoexcited et is a particluar candidate for this effect, especially for excitations to high-lying states. However, for systems with D-A energies in the HOMO/LUMO gap, our results suggest a reasonably constant value for $\beta$.

\section{Conclusions}

Our results show that water can have a dramatic effect on $H_{\mathrm{ab}}$ between donor and acceptor in solution. The intervening water leads to a significant increase in the electronic coupling at a given $\mathrm{D}-\mathrm{A}$ distance, and the decay of $H_{\mathrm{ab}}$ with distance is reduced considerably. Our results suggest that the coupling is influenced by the water orientation between the donor and acceptor, but we find a general exponential decay with distance of $H_{\mathrm{ab}} . \beta$ appears to be relatively weakly dependent on D-A energy for states in the water HOMO-LUMO gap. It also appears that ab initio calculations of $H_{\mathrm{ab}}$ would lead to somewhat smaller values for $\beta$ than those obtained at the INDO level.

Acknowledgment. The authors gratefully acknowledge helpful discussions with Dr. Barry Olafson, Dr. Siddarth Dasgupta, and Dr. Liem Dang. Helpful suggestions by the referees are also gratefully acknowledged. Financial support of this research was provided by the Camille and Henry Dreyfus Foundation through a Camille and Henry Dreyfus TeacherScholar award (R.J.C.), the donors of the Petroleum Research Fund, and the National Science Foundation (CHE-9731634). The computations were performed on the Harvey Mudd College Computational Chemistry Facility, the establishment of which was made possible by a grant from the National Science Foundation (Grant CHE-9512467).

\section{References and Notes}

(1) Marcus, R. A. J. Chem. Phys. 1965, 43, 679 and references therein

(2) Hush, N. S. Trans. Faraday Soc. 1961, 57, 557.

(3) Levich, V. G.; Dogonadze, R. R. Collect. Czech. Chem. Commun. 1961, 26, 193.

(4) Kestner, N. R.; Logan, J.; Jortner, J. J. Phys. Chem. 1974, 78, 2148.

(5) Brunschwig, B. S.; Logan, J.; Newton, M. D.; Sutin, N. J. Am. Chem. Soc. 1980, 102, 5798.

(6) Zusman, L. D. Chem. Phys. 1980, 49, 295.

(7) Jortner, J.; Bixon, M. J. Chem. Phys. 1988, 88, 167.

(8) Marcus, R. A.; Sutin, N. Biochim. Biophys. Acta 1985, 811, 265.

(9) Newton, M. D.; Sutin, N. Annu. Rev. Phys. Chem. 1984, 35, 437.

(10) Miller, J. R. J. Phys. Chem. 1978, 82, 767; J. Phys. Chem. 1975, 79, 1070 .

(11) Miller, J. R.; Beitz, J. V. J. Chem. Phys. 1981, 6746.

(12) Miller, J. R. Hartman, K. W.; Abrash, S. J. Am. Chem. Soc. 1982, 104,4296

(13) Jordan, K. D.; Nactigallova, D.; Paddon-Row: M. N. In Modern Electronic Structure Theory and Applications in Organic Chemistry; E. R. Davidson, E. R., Ed.; World Scientific: NJ, 1997; p 257.

(14) Newton, M. D. Chem. Rev. 1991, 91, 767.

(15) Newton, M. D.; Cave, R. J. In Molecular Electronics; Ratner, M. A. Jortner, J., Eds., IUPAC: London, 1996; p 73.

(16) Gould, I. R.; Young, R. H.; Mueller, L. J.; Albrecht, A. C.; Farid, S. J. Am. Chem. Soc. 1994, 116, 3147; J. Am. Chem. Soc., 1994, 116, 8188 .

(17) Kumar, K.; Lin, Z.; Waldeck, D. H.; Zimmt, M. B. J. Am. Chem. Soc. 1996, 118, 243.

(18) (a) Oliver, A. M.; Craid, D. C.; Paddon-Row: M. N.; Kroon, J. Verhoeven, Chem. Phys. Lett. 1988, 150, 366. (b) Lawson, J. M.; Paddon- 
Row, M. N.; Schuddeboom, W.; Warman, J. M.; Clayton, A. H.; Ghiggino, K. P. J. Phys. Chem. 1993, 97, 13099.

(19) Newton, M. D. Int. J. Quantum Chem., Quantum Chem. Symp. 1980, $14,363$.

(20) Logan, J.; Newton, M. D.; Noell, J. O. Int. J. Quantum Chem., Quantum Chem. Symp. 1985, 18, 213.

(21) Newton, M. D. J. Phys. Chem. 1988, 92, 3049.

(22) Larsson, S. J. Phys. Chem. 1984, 88, 1321.

(23) Henderson, T. M.; Cave, R. J. J. Chem. Phys. 1998, 109, 7414.

(24) (a) Cave, R. J.; Newton, M. D.; Kumar, K.; Zimmt, M. B. J. Phys.

Chem. 1995, 99, 17501. (b) Wander, M.; Cave, R. J. Unpublished results.

(25) Kumar, K.; Kurnikov, I. V.; Beratan, D. N.; Waldeck, D. H.; Zimmt,

M. B. J. Phys. Chem. A 1998, 102, 5529.

(26) Marchi, M.; Chandler, D. J. Chem. Phys. 1991, 95, 889.

(27) Mosyak, A.; Nitzan, A.; Kosloff, R. J. Chem. Phys. 1996, 104, 1549.

(28) Benjamin, I.; Evans, D.; Nitzan, A. J. Chem. Phys. 1997, 106, 1291.

(29) Benjamin, I.; Evans, D.; Nitzan, A. J. Chem. Phys. 1997, 106, 6647.

(30) Cave, R. J.; Newton, M. D. J. Chem. Phys, 1997, 106, 9213.

(31) Jorgensen, W. L.; Chandresekhar, J.; Madura, J. D.; Impey, R. W.; Klein, M. L. J. Chem. Phys. 1983, 79, 926.

(32) Dang, L. X.; Pettitt, B. M. J. Phys. Chem. 1987, 91, 3349.

(33) Reimers, J. R.; Watts, R. O. Chem. Phys. 1984, 91, 201.

(34) Levitt, M.; Hirshberg, M.; Sharon, R.; Laidig, K. E.; Daggett, V. J. Phys. Chem. B, 1997, 101, 5051.

(35) The Cerius ${ }^{2}$ program suite is a product of Molecular Simulations, Inc., San Diego, CA.

(36) Cave, R. J.; Newton, M. D. Chem. Phys. Lett., 1996, 249, 15.

(37) The INDO program suite was developed by Michael C. Zerner and co-workers at the University of Guelph, Ontario, Canada, and at the University of Florida, Gainsville.
(38) a) Mulliken, R. S. J. Am. Chem. Soc. 1952, 64, 811. (b) Mulliken, R. S.; Person, W. B. Molecular Complexes; Wiley: New York, 1969.

(39) a) Hush, N. S. Prog. Inorg. Chem. 1967, 8, 391. (b) Hush, N. S. Electrochim. Acta 1968, 13, 1005. (c) Reimers, J. R.; Hush, N. S. J. Phys. Chem. 1991, 95, 9773.

(40) Roos, B. O. Adv. Chem. Phys, 1987, 69, 399

(41) MOLCAS, version 3; Andersson, K.; Fülscher, M. P.; Karlström, G.; Lindh, R.; Malmqvist, P.-Ä.; Olsen, J.; Roos, B. O.; Sadlej, A. J. University of Lund, Sweden; Blomberg, M. R. A.; Siegbahn, P. E. M University of Stockholm, Sweden; Kellö, V.; Noga, J.; Urban, M. Caimans University, Slovakia; Widmark, P.-O. IBM, Sweden, 1994.

(42) Wachters, A. J. H. J. Chem. Phys. 1970, 52, 1033.

(43) Raffenetti, R. C. J. Chem. Phys. 1973, 58, 4452.

(44) a)Widmark, P.-O.; Malmqvist, P.-Å.; Roos, B. O. Theor. Chim. Acta 1990, 77, 291. (b) Widmark, P.-O.; Persson, B. J.; Roos, B. O. Theor. Chim. Acta, 1991, 79, 419.

(45) Benedict, W. S.; Gailer, N.; Pyler, E. K. J. Chem. Phys. 1956, 24, 1139

(46) In the "perp", or perpendicular orientation the $\mathrm{O}$ atom of water is located on the $\mathrm{Zn}-\mathrm{Zn}$ line of centers, with the water molecular plane perpendicular to the $\mathrm{Zn}-\mathrm{Zn}$ axis. In the $C_{2 v}$ orientation, the $\mathrm{O}$ atom of the water is located on the $\mathrm{Zn}-\mathrm{Zn}$ line of centers, with the water $C_{2 v}$ axis along the $\mathrm{Zn}-\mathrm{Zn}$ axis. In the $\mathrm{OH}$ orientation, an $\mathrm{OH}$ bond in water is located along the $\mathrm{Zn}-\mathrm{Zn}$ line of centers.

(47) Davis, W. B.; Wasielewski, M. R.; Ratner, M. A.; Mujica, V.; Nitzan, A. J. Phys. Chem. 1997, 101, 6158.

(48) Medvedev, E. S.; Stuchebrukhov, A. A. J. Chem. Phys., 1997, 107 3821.

(49) Daizedeh, I.; Medvedev, E. S.; Stuchebrukhov, A. A. Proc. Natl. Acad. Sci. 1997, 94, 3703. 